\section{Sistemas de Controlo de Acesso}

RESUMO

A segurança, o conforto, a funcionalidade e a fiabilidade dos sistemas que integram as instalações são aspectos fundamentais na qualidade de vida das pessoas.

Os sistemas de controlo de acessos são, cada vez mais, um elemento facilitador da gestão dos espaços essenciais à dinâmica funcional das instalações e um meio imprescindivel de controlo da actividade nas organizações.

O presente artigo aborda a temática do controlo de acessos, no que se refere, essencialmente, aos aspectos técnicos e tecnológicos dos mesmos.

\section{INTRODUÇão}

Os sistemas de controlo de acesso visam a permissão de acesso, em função de parâmetros pré-ajustados, tais como, locais de acessos, horários de acesso,....

A sua base de funcionamento é a permissão de acesso apenas a utilizadores autorizados.

O sistema de controlo de acessos pode ser interligado a sistemas de gestão técnica centralizada, sistemas automáticos de detecção de intrusão e sistemas de vídeo vigilância, integrando e complementando o funcionamento destes sistemas.

\section{FUnções PRINCIPAIS}

As funções principais de um sistema de controlo de acessos são:

- Definição de áreas de acesso;

- Definição de direitos de acesso por área;

- Definição de horários de acesso;

- Definição de percursos de acesso;

- Seguimento e localização;

- Registo automático de entradas e saídas;

- Alarme em caso de entrada forçada em zonas com acesso condicionado.

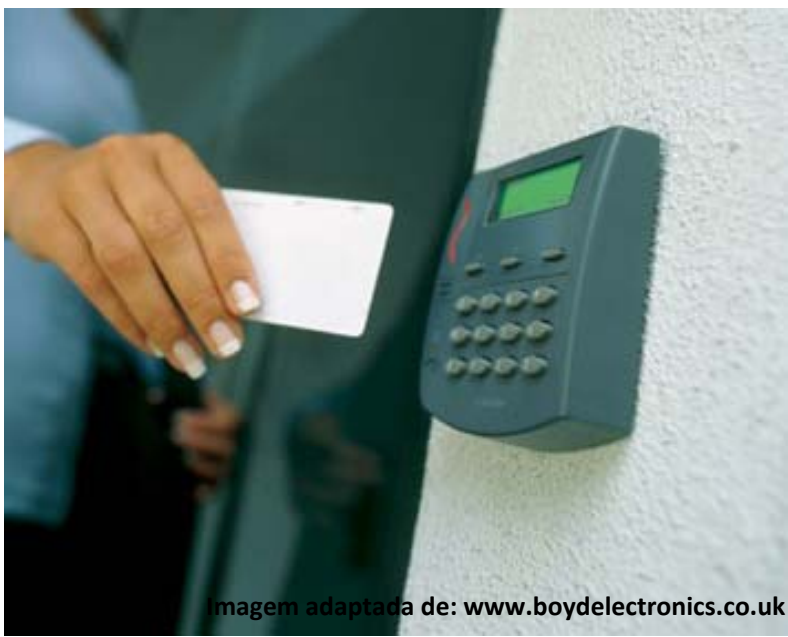

3 Principais Vantagens

As principais vantagens de um sistema de controlo de acessos são:

- Segurança

- Fiabilidade

- Conforto

- Flexibilidade

- Integração

\section{Constituiç̧̃̃o Geral do Sistema}

A figura 1, mostra a arquitectura geral de um sistema de controlo de acessos:

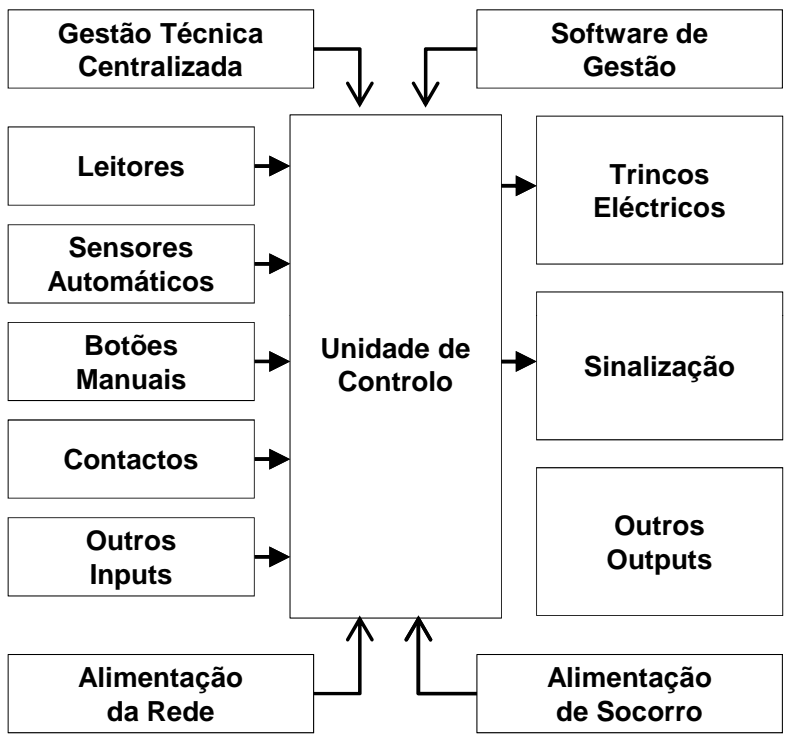

Figura 1 - Constituição geral de sistema de controlo de acessos 


\subsection{UNIDADE DE CONTROLO}

A Unidade de Controlo é o "cérebro" do sistema. É neste equipamento que são ligados todos os periféricos (leitores, sensores, botões, trincos eléctricos,...) e a partir do qual sairá, ou não, uma ordem de abertura, dependendo das definições de acessos e da validade dos dados recebidos pelos elementos periféricos.

Os sistemas de controlo de acessos dividem-se em dois grupos principais:

- Sistemas em Rede;

- Sistemas Stand Alone.

\subsection{LEITORES}

São o meio de interacção do utilizador com o sistema.

Podem ser de diversos tipos:

- Teclado;

- Banda Magnética;

- Proximidade;

- Códigos de barras;

- Ópticos;

- Biométricos (leitura da íris, impressão digital)

Podem ainda combinar duas ou mais das tecnologias acima referidas.

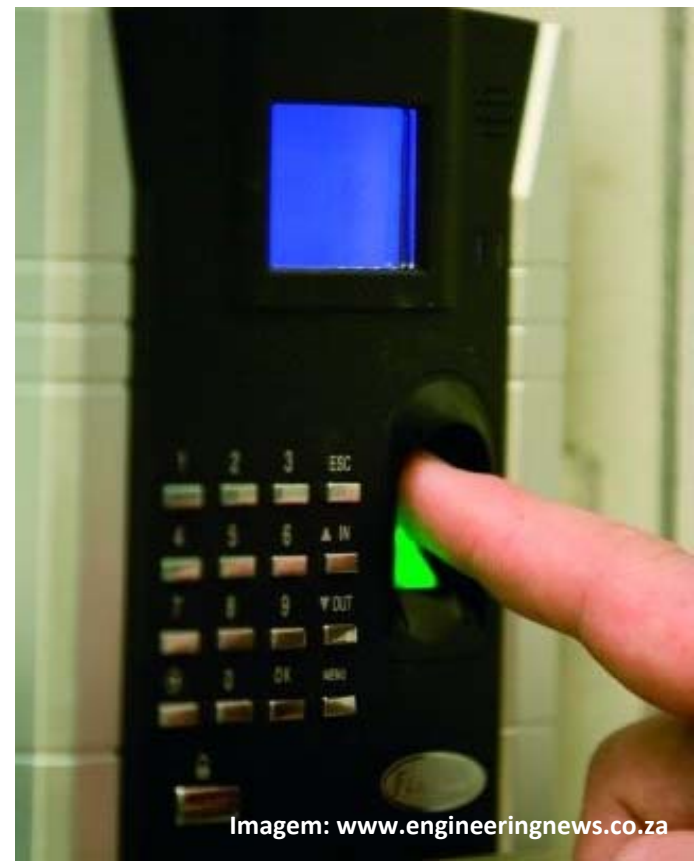

\subsection{CONTACTOS}

São os elementos de informação do estado do sistema.

Podem ser de dois tipos:

- Magnéticos;

- Mecânicos.

\subsection{BOTÕES MANUAIS}

São utilizados normalmente como elementos de saída, quando não se justifique a utilização de leitores nos dois lados das portas.

Estes botões quando pressionados, actuam um contacto que vai gerar o pedido de abertura à central de controlo de acessos.

\subsection{CARTÕES}

São utilizados em alguns dos sistemas anteriormente referidos. Para esses sistemas, os cartões são as chaves do sistema.

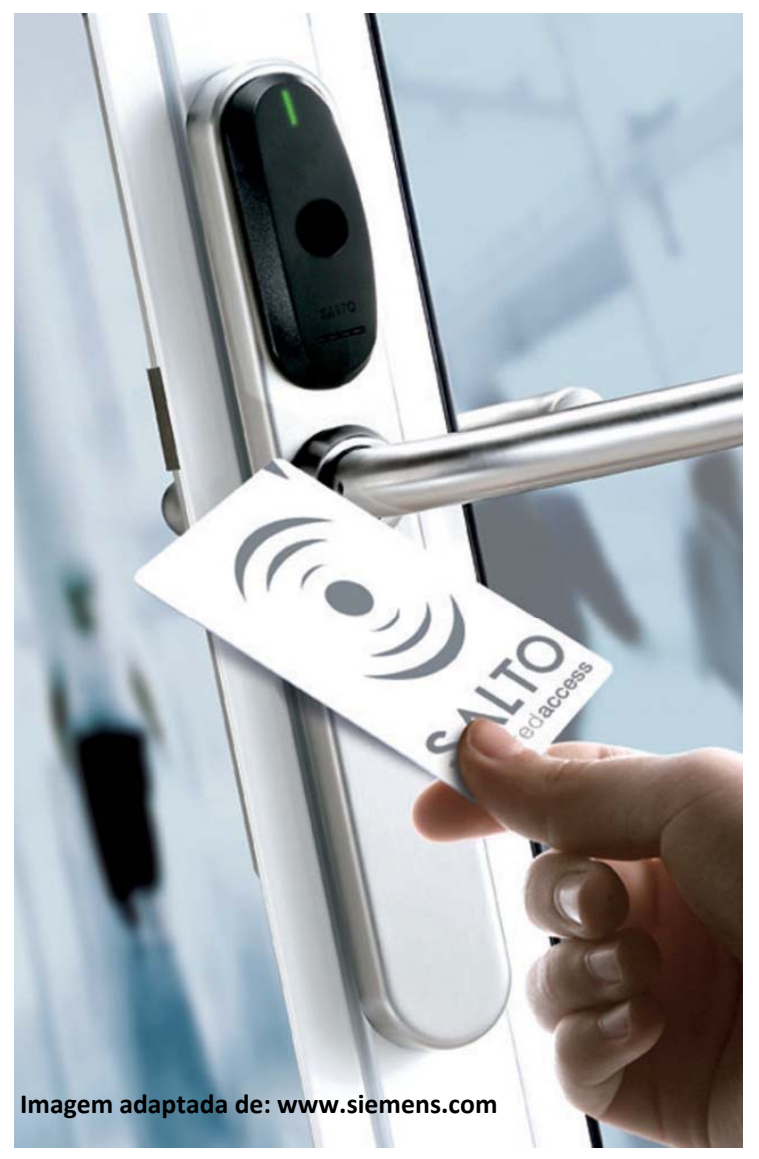




\subsection{TRINCOS ELÉCTRICOS}

São as fechaduras do sistema. Permitem, para utilizadores autorizados, a abertura das portas e o acesso aos espaços.

\subsection{ALIMENTAÇÃo do SISTEMA}

A alimentação de energia eléctrica do sistema em condições normais de funcionamento deverá ser realizada através da rede de energia eléctrica devendo para o efeito ser prevista uma alimentação vinda do Quadro Eléctrico da instalação.

O sistema deverá ainda ter uma alimentação própria de socorro que garanta o seu funcionamento em caso de falha da alimentação normal da rede.

\subsection{SoftwARES DE GESTÃo}

Destinam-se, essencialmente, a controlar e gerir a totalidade do sistema de controlo de acessos a partir de um ou diversos postos.

Através de interfaces gráficas, o utilizador, gere de uma forma simples e intuitiva a totalidade do(s) sistema(s).

Para além da gestão e supervisão de funcionamento dos sistemas que recebe, permitem a geração de relatórios com os eventos recebidos pelo sistema, tornando-se numa ferramenta muito útil para gestores e responsáveis de empresas e entidades.

\subsection{GESTÃo TÉCNICA CENTRALIZADA}

A Gestão Centralizada consiste na integração dos diversos sistemas existentes numa instalação para que o seu comando, controlo e operação possam ser realizados de uma forma centralizada num sistema de gestão.

A gestão centralizada normalmente só é utilizada em instalações grandes e complexas, de forma a facilitar o comando, controlo e operação dos diversos sistemas.

\section{Considerações FinaIS}

Este artigo visou abordar aspectos técnicos, tecnológicos e conceptuais, dos sistemas de controlo de acessos.

Os sistemas de controlo de acesso são sistemas tecnologicamente maduros e que cada vez mais são uma realidade nas instalações, potenciando uma mais eficaz gestão dos espaços e dos utentes desses mesmos espaços, de uma forma segura, simples, fiável e económica.

Em instalações com sistemas de controlo de acessos, a alteração das condições de acesso de um utilizador, é realizada de uma forma simples, rápida, cómoda e económica, contrariamente às instalações tradicionais.

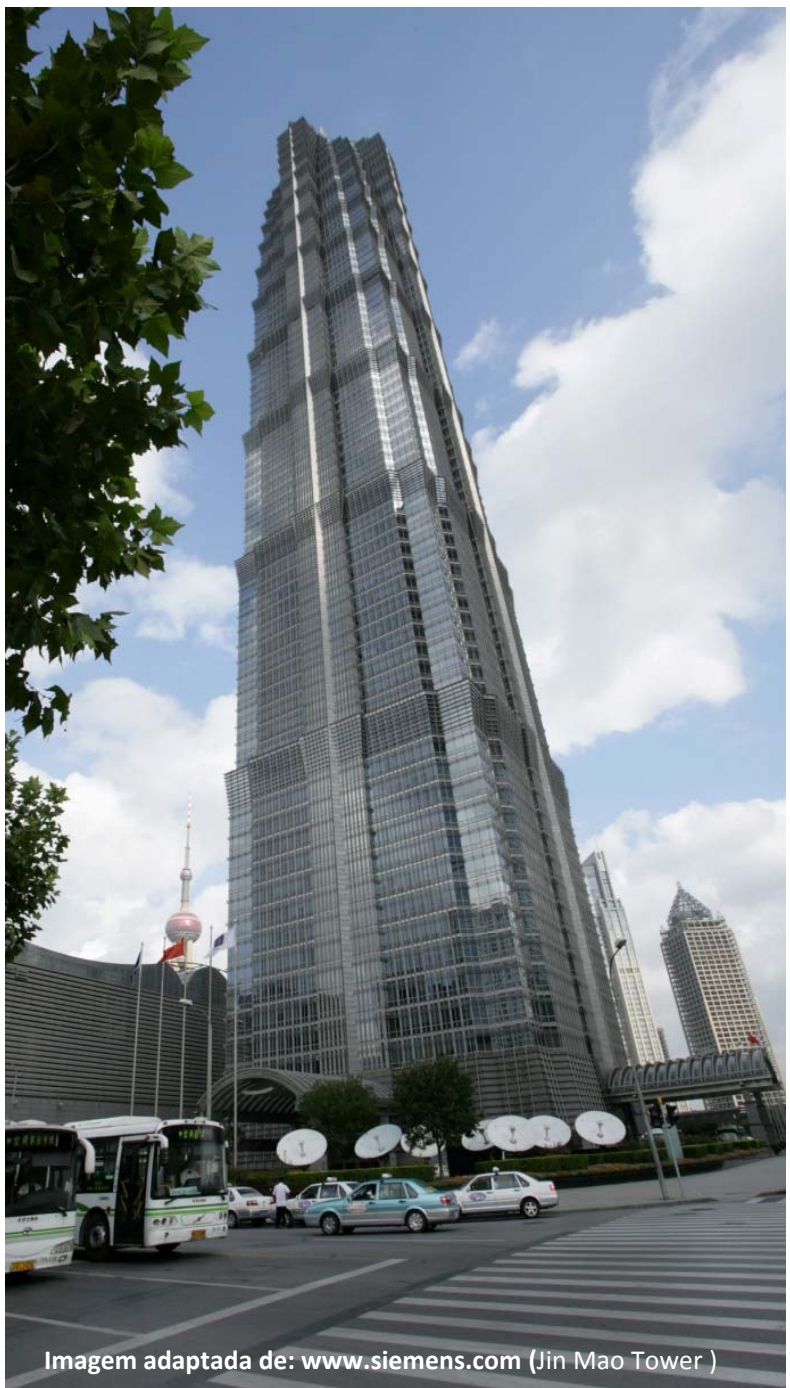

